\title{
Helping Friends: a peer support program for senior secondary schools
}

\author{
John Dillon $^{1}$ and Anne Swinbourne ${ }^{2}$
}

\author{
1. Tropical Population Health Network, Queensland Health, Townsville, Queensland, Australia \\ 2. Department of Psychology, James Cook University, Townsville, Queensland, Australia
}

\begin{abstract}
Peer support is used frequently in addressing the health of young people. Helping Friends builds on the existing peer helping networks in schools to improve the availability, accessibility and appropriateness of social and personal support. It increases young people's knowledge of and access to referral options (in and out of school) and assists in the development of a safe and supportive school environment. Twenty-two schools in North Queensland, Australia participated in the program with many participating on several occasions. An evaluation of the Helping Friends program using the Social Provision Scale (Cutrona \& Russell, 1987) was undertaken to determine whether there was an increase in perceived social support as hypothesised. Results revealed small yet significant increases along subscales of the Social Provision Scale. Pre and post measures of helping skills and knowledge of helping topics also revealed a significant increase following students' participation in training workshops. The results are discussed in terms of the efficacy of peer support programs for addressing the health needs of young people. The findings can be used to guide secondary schools in making decisions on the value of peer support programs and their application in school and out of school settings.
\end{abstract}

\section{Keywords}

peer support, social support, schools, connectedness, school mental health program, help seeking, program evaluation

\section{Introduction}

Every school has many informal helping networks and young people typically seek out their peers when confronted with problems. The capacity of peer support programs to help students recognise and identify issues before they manifest into more serious problems is considered an appropriate early intervention strategy for this age group.

The body of research on the health of young people indicates that although they are generally physically healthy, they have some consistent and difficult issues to cope with that may affect their physical and psychological wellbeing. The problems that young people face include: the use of alcohol and other drugs, unsafe sexual practices and early pregnancy, suicide and selfharm, accidents and injuries, eating disorders, violence, criminal behaviour, depression and mental illness, and the temporary and permanent breakdown of family and social relationships (Blum \& Rinehart, 1997). The National Health and Medical Research Centre (NHMRC, 1997) reported that between 15 and 40 per cent of young people report symptoms of depressed mood and up to 24 per cent will have suffered at least one major depressive episode by the time they are 18 years of age.

Contact: John Dillon, Principal Consultant, Organisational Culture, Northern Area Health Service, Queensland Health, IMB53, PO Box 670, Townsville, Queensland 4810 Australia john_dillon@health.qld.gov.au

Citation: $\quad$ Dillon, J. \& Swinbourne, A. (2007). Helping Friends: a peer support program for senior secondary schools. Australian e-Journal for the Advancement of Mental Health, 6(1), www.auseinet.com/journal/vol6iss1/dillon.pdf

Published by: Australian Network for Promotion, Prevention and Early Intervention for Mental Health (Auseinet) www.auseinet.com/journal

Received 15 August 2006; Revised 9 March 2007; Accepted 9 March 2007 
From a variety of studies conducted across Canada, the United States and Australia, Carr (1987), Sawyer, Arney, Baghurst et al. (2000) and Rickwood, Deane, Wilson and Ciarrochi (2005), have found that most young people rely on their friends for help and that very few go to counsellors or other sources in the first instance. Carr suggests therefore that prevention programs targeting young people need to be directed at peers to strengthen (or immunise) students against harmful influences. Providing skills in resolving problems more effectively and reducing the incidence of psychologically destructive factors within the environment are central to his proposal. Coggan, Patterson and Fill (1997) reinforce his view that young people rarely access services and turn to their peers or close friends when in crisis situations. They also identified that barriers to young people attending professional services may be overcome by increasing their knowledge about the services that are available.

Personal support is fundamental to friendships but the level of social support or connectedness is considered an equally important protective factor in maintaining or regaining young people's mental health. Indeed, feelings of connectedness to school have been the only aspect of the school environment to be consistently associated with better health and the avoidance of risky behaviours among students (Blum \& Rinehart, 1997).

Glover, Burns, Butler and Patton (1998), in their discussion of an Australian school-based study exploring the need for prevention programs in early adolescence, found students who reported low levels of connectedness to school were between two and three times more likely to experience depressive symptoms when compared with peers who enjoyed higher levels of connectedness. Forty per cent of the young people surveyed stated that they did not have anyone who knew them very well, and that nearly a quarter had no-one to talk to if they were upset, no-one they could trust, and no-one to depend on (Glover et al., 1998).

In surveys, small group discussions, and focus groups with over 1200 young people, Keys Young (1997), found that 43 per cent of respondents sought help from a friend the same age when it was needed. This course of action was the second most frequently mentioned response after talking to a family member or partner. They were generally thought to be more sympathetic and better able to relate to the situation. Seeking assistance from peers is also well documented through more recent research including The Queensland Young People's Mental Health Survey (Donald, Dower \& Lucke, 2000) and Footprints to the Future (Prime Minister's Youth Pathways Action Plan Taskforce, 2001).

Social support has been found in numerous studies to be a predictor of better health and wellbeing. Frydenberg (1997) reported that social support offers benefits in three ways - a source of acceptance and intimacy, useful information and guidance, and support in the form of services and resource assistance.

In summary, the research consistently reports that peers in the school environment are the most likely source of help for young people in crisis, and that having supportive friends is a strong protection against diminished mental health and other problems. It also indicates the issues that underlie the health and wellbeing of young people that need to be addressed: forming connections with others, developing problem solving skills, assisting friends to access professional services, and identifying warning signs. These tenets have guided the development and implementation of the Helping Friends program.

\section{Method}

\section{Participants}

Since 1990, 22 schools in North Queensland have participated in the Helping Friends program. The majority of recruitment has occurred in the period 1999-2003, with only 5 schools recruited prior to this time period. Most of the participating schools were Government high schools and all schools were coeducational. Just over half the schools have participated in the program only once although this reflects the recency of schools initiating the program. Around one quarter have held the program twice, with the remainder of schools 
running the program over 3 or 4 years. The program was promoted to school based youth health nurses and teaching staff and it was these individuals who indicated their willingness to take up the program to health promotion staff.

In the early years of program delivery, feedback from schools was sought and the program and its evaluation were refined to reflect the feedback. Therefore the exact data collected may vary over years. The program and evaluation protocols were finalised in 2001. Complete data sets consistent over different years is therefore available for 10 instances of program delivery involving 12 schools and the results presented here are based on these schools unless otherwise stated. It should be noted that the program had the capacity to be delivered to two schools simultaneously; therefore the number of schools involved may exceed the number of times the program has been delivered. Schools were paired for logistical reasons (the sharing of support staff, e.g. guidance officer, school nurse), geographical reasons (only two secondary schools in the town) and for presentation reasons (group dynamics).

\section{Materials}

The Helping Friends program is an adaptation of the Natural Helpers program (Comprehensive Health Education Foundation, 1997). It includes a program overview (describing the rationale and instructions for planning and implementing the program), a facilitator's manual (containing the program content and guidelines for presentation), participant workbooks (activity sheets and handouts used in the workshop) and CD ROM (PowerPoint presentation and templates for program documentation).

\section{Social Provision Scale}

The Social Provision Scale (SPS) (Cutrona \& Russell, 1987) is a closed item questionnaire designed to assess an individual's perception of the extent of their social support. Respondents are asked to use a 4-point scale to indicate the degree to which they agree or disagree with each of 24 statements. Possible scores on each item range from 1-4 and half of the items are reverse scored. Summing scores on each item yields a total score for the SPS ranging between 24 and
96. Higher scores indicate greater perceived social support. The combination of specific items yields 6 subscales. The subscales were designed to reflect the theoretical work of Weiss (1974), who hypothesised that in order to feel socially supported an individual's social network needs to fulfill six functions or provisions. The SPS subscales reflecting these provisions are:

1. Guidance: provision of advice or information

2. Reassurance of Worth: recognition by others of one's competence and value

3. Social Integration: a sense of belonging to a group of similar others

4. Attachment: emotional closeness to another individual which provides a sense of security

5. Nurturance: knowing that others rely upon an individual for emotional and physical well-being

6. Reliable Alliance: knowing that there are others that can be relied upon for help.

Each subscale contains 4 items and thus has scores ranging between 4 and 16 . Scores for each provision are obtained by summing the item scores. Higher scores indicate that the respondent perceives that they gain more of the provision of interest from their social relationships than do low scoring individuals.

\section{School Issue Scale}

A list of issues that students encounter regularly was generated by literature review and discussion with expert informants (e.g. school staff and senior students). This list (see Table 1) was used as a starting point to assess which issues were most prevalent and important to students in each school.

Table 1. Issues listed on pre program assessment form

\begin{tabular}{ll}
\hline Achieving at school & Relationships with friends \\
Depression & Sexual relationships \\
Alcohol and drug use & Sexual preference \\
Family relationships & Racial tension \\
Bullying/gossip & Stress and anxiety \\
Life after school & Body image \\
\hline
\end{tabular}




\section{Knowledge and attitudinal assessment}

An 18-item scale derived from topics addressed in the training workshop was developed to assess knowledge and attitudes towards helping behaviours. Each item consisted of a statement with which individuals had to indicate their agreement on a 7-point scale anchored at either end with 'Strongly disagree' and 'Strongly agree'. The mid-point of the scale was labeled 'Unsure'. Examples of items are statements such as 'A quick decision is a good decision' and 'Hearing and listening is the same thing'. Half the items were reverse scored. Scores on each item were then summed and a total score calculated. Scores ranged from 18 to 126 with higher scores indicating more favourable attitudes towards helping behaviours and better knowledge of helping skills.

\section{Procedure}

The SPS was administered to all Year 11 students in the participating schools prior to the Helping Friends program taking place. At the same session students were asked to nominate individuals from both the staff and Year 11 student body who they perceived as someone they could approach if they had a problem. Additionally all students were asked to indicate the life issues they felt other students were most likely to experience. Data from this section of the initial questionnaire are not presented in this article.

The most frequently nominated staff and students were contacted by a School Coordinator (typically a guidance officer or school nurse) and invited to participate in the training workshop. It is interesting to note that nominations for female helpers exceeded male helpers (approx. ratio of $2: 1$ ) and this was reflected in the subsequent participation in the program. Participation for these individuals was voluntary and very few such individuals declined to participate. Parental consent was obtained prior to the program starting. Students were informed that they could opt out of the program at any time, and there would be no promotion of their role beyond their existing friendship groups. Program delivery catered for 30 to 40 participants per workshop and was conducted over a 2 day period away from the school campus. Facilitation of the program was undertaken by health promotion officers and school based youth health nurses with support from other school staff as required. Workshop topics were presented sequentially and focused on helping relationships, communication skills, problem solving, decision making, referral and self care. One session of the workshop focused on issues of concern to students at the schools represented at the workshop. Such issues were identified from the School Issue Scale. Mixes of theory and skill rehearsal sessions, and a variety of audio-visual materials using popular movies and music, were used to convey and reinforce key messages throughout.

Prior to the commencement of training, participants were asked to complete a preworkshop questionnaire which consisted of the 18-item knowledge and attitudes questionnaire and a brief survey of the number of people that had approached them for help in the last 6 months, the types of issues they had talked about and the perceived severity of the problem. This questionnaire package was also completed one month after the training workshop along with another brief survey of the use participants had made of the skills and knowledge presented during training. Feedback from the participants on their satisfaction with the content and delivery of the training workshops was also collected.

Six months after the conclusion of the training program, the student body was again asked to complete the SPS. All responses were anonymous.

\section{Results}

\section{Social Provision Scale}

The analysis was conducted using the school as the unit of measurement as the SPS was being used as an indicator of any change in the perceived supportiveness of the school environment. The SPS was filled out anonymously by all the students in Year 11 at each of the participating schools. This occurred prior to and 6 months after program delivery. Scores for each school were calculated by averaging student responses along each provision. Pre and post program SPS data was 
available for 10 instances of program delivery. Repeated measures t-tests were conducted to test the hypothesis that mean scores on all provisions would improve post program.

Table 2. Mean scores and standard deviations for each provision

\begin{tabular}{lcccccc}
\hline Provision & \multicolumn{2}{c}{$\begin{array}{c}\text { Pre } \\
\text { program }\end{array}$} & & \multicolumn{2}{c}{$\begin{array}{c}\text { Post } \\
\text { program }\end{array}$} \\
\cline { 2 - 3 } \cline { 6 - 7 } & Mean & SD & & Mean & SD \\
\hline Guidance & 12.5 & .71 & & 12.8 & .29 \\
Reassurance of Worth* & 11.4 & .55 & & 11.8 & .31 \\
Social Integration & 12.5 & .86 & & 12.8 & .21 \\
Attachment* & 12.0 & .67 & & 12.5 & .29 \\
Nurturance* & 11.2 & .52 & & 11.6 & .23 \\
Reliable Alliance & 12.6 & .90 & & 12.9 & .25 \\
\hline
\end{tabular}

* Significant pre/post increase at $p<.05$

Table 2 shows the mean scores on each of the provisions over the 10 instances of program delivery. The SPS subscales are scored on a scale ranging from 4-16. On average schools scored quite well on each subscale and increases in mean scores pre and post program were observable along all provisions. However only the increases for the provisions of Reassurance of Worth, Attachment and Nurturance were statistically significant. This may be due to a ceiling effect. Examination of the table indicates that those provisions showing a significant increase were also the ones with the lower averages pre-program.

\section{Knowledge and attitudinal assessment}

The 18-item knowledge and attitudinal scale was administered prior to the selected staff and students undergoing the workshop training and again 1 month after the workshop. Given that higher scores on the scale indicate more positive attitudes towards helping behaviours and higher perceived competency in the use of helping skills, an increase in scores pre to post workshop was expected. In total 101 students completed both the pre and 1 month post workshop versions. Prior to the workshop the average score on the scale for the group was $78.7 \pm 6.4$. One month post workshop the average score had increased significantly to $84.8 \pm 7.0\left(\mathrm{t}_{100}=-8.2\right.$, $\mathrm{p}<.001)$.

\section{Use of skills learnt in the workshop}

At the 1 month assessment, participants were asked to rate the frequency with which they had used the skills presented in the workshop when helping or discussing their friends' problems. Table 3 shows the breakdown of frequency of use by specific skills for the 101 individuals completing the follow up questionnaire.

Not surprisingly the most frequently practiced skills were those to do with verbal and nonverbal communication and active listening. The least frequently used skills were those concerning the accessing of outside help or referring friends to people who could help them. Given the time scale of one month between training and the administration of this questionnaire, this pattern of results is not surprising.

Table 3. Frequency of use of each of the skills learnt in the workshop

\begin{tabular}{lccr}
\hline & \multicolumn{3}{c}{$\begin{array}{c}\text { Frequency of skill use in last } \\
\text { month (\% of respondents) }\end{array}$} \\
\hline Skill & $\begin{array}{r}\text { Not at } \\
\text { all }\end{array}$ & $\begin{array}{r}\text { 1-3 } \\
\text { times }\end{array}$ & $\begin{array}{c}\text { 4 times } \\
\text { or more }\end{array}$ \\
\hline $\begin{array}{l}\text { Non-verbal } \\
\text { communication }\end{array}$ & 14.4 & 56.7 & 28.9 \\
$\begin{array}{l}\text { Verbal communication } \\
\text { Active listening }\end{array}$ & 17.6 & 26.4 & 56.0 \\
Decision making & 22.2 & 32.2 & 45.6 \\
$\begin{array}{l}\text { Problem solving } \\
\text { Accessing outside }\end{array}$ & 18.7 & 51.6 & 29.7 \\
help & 31.9 & 54.9 & 13.2 \\
Referral processes & 72.2 & 11.1 & 16.7 \\
Assessing risk & 52.7 & 30.8 & 16.5 \\
$\begin{array}{l}\text { Understanding own } \\
\text { limits }\end{array}$ & 26.4 & 57.1 & 16.5 \\
\hline
\end{tabular}

\section{Program satisfaction}

Participant satisfaction levels with the content and presentation of the program were consistently high across school, gender and time. A simple feedback sheet revealed greater than $90 \%$ agreement with a series of statements about the favourable coverage of topics and delivery. 


\section{Discussion}

\section{Social Provision Scale}

The Helping Friends program was associated with statistically significant increases along three subscales of the Social Provision Scale. These increases were as hypothesised given that the aim of the program was to increase individuals' perceived social support.

While the increases along the provision scale were significant they also tended to be small. As stated earlier this may indicate the operation of a ceiling effect. Some evidence for this view comes from examination of the data at the level of the individual school. Schools with high mean scores along the provision subscales tended not to report significant increases post program. In contrast, schools where the mean scores tended to be lower pre program also appeared to be the schools reporting significant improvements post program.

The major threat to the validity of any conclusions drawn from this data is that of maturation. It may be that the passing of time influences the degree of an individual's perceived social support. For example, students at the beginning of the school year may not feel well integrated into the student body. However by the end of the year this integration has taken place as familiarity with their peers increases and friendships are formed. Therefore perhaps the mere passage of time may be responsible for the observed effects. While difficult to comprehensively assess without a control group, the maturation explanation is unlikely. The schools enrolled in the program are regional schools whose constituency is drawn from a distinct geographical area. The students involved in the program were all senior students, the majority of whom had completed their junior secondary schooling with the same peer group. They were therefore already familiar with the people in their year level. Additionally, not all the pre program assessments were done at the beginning of the year. Schools ran the program as it suited them. Some schools initiated the program mid-year and others enrolled in the program even later in the year and performed the post program assessment in the first term of the following school year. Thus whatever maturational effects existed could not be systematic.

Peer support programs have been operating for many years but few have evaluated their effectiveness beyond satisfaction levels of participants and reviews of their activity as helpers. This study indicates that there is value beyond the direct participation in such programs to broader friendship groups and whole cohorts of students in senior secondary schools. As previous research has indicated, young people do approach their peers initially when seeking assistance, reassurance or guidance. The results from this study indicate that strengthening and upskilling of existing social supports can fulfill an important role in the improvement and/or maintenance of well-being among senior secondary students. Social support and connectedness has been identified as an important protective factor against a range of physical and psychological conditions. The provision of early intervention in the development of these conditions is now accepted as good practice and can avoid more complex and costly treatment regimes later. The ability of peers to provide support to their friends and an assessment of any subsequent course of action is central to the value of this program.

\section{Knowledge transfer and skill application}

Follow up at one month post training demonstrated a significant increase in knowledge of helping behaviours and the use of core skills required for personal and social support; responses to 'accessing outside help' and 'referral processes' being the exception. The limited use of these skills may simply reflect the short time period between the workshop and the follow up or the absence of any reason to refer on. The finding may also reflect the paucity of appropriate 'youth-friendly' services in some locations, especially outside metropolitan and provincial areas.

\section{Conclusion}

The Helping Friends program is associated with statistically significant increases along a measure of perceived social support and has been effective in increasing knowledge of helping behaviour among participants. There has been widespread use of the helping skills promoted in 
the training workshops and participants, staff members and principals have endorsed the value of the program. Anecdotal feedback from key informants within the schools suggests that there had been a number of identifiable incidents in and out of school hours which had been managed better as a result of the program.

Schools that have implemented Helping Friends on more than one occasion are exploring optimal ways of adopting the program within existing curriculum programming. As their confidence with it increases they are tailoring the training workshop to better meet the individual needs and circumstances of their school. The follow-up to the workshop and the ongoing support for the Helping Friends program within the school has been a critical factor in determining the long term effectiveness of the strategy.

Peer influence is an important consideration in designing programs that target adolescent health (Carr, 1987). Further research is needed to understand how peer support programs like Helping Friends can impact on a range of health behaviours, but also how peer influence can intervene early to address issues before they manifest into more serious situations. Opinion leaders within friendship groups can exert both positive and negative influence on young people's decisions around their health and well being. This study has been able to provide evidence to suggest that identifying respected friends and reinforcing their existing skills can reinforce the level of social support within and across peer groups. Social connectedness and a sense of belonging have been proposed as central themes to positive mental health outcomes (Kawachi \& Berkman, 2001) and programs that promote and galvanise these desirable individual and social outcomes should continue to be encouraged.

\section{References}

Blum, R. \& Rinehart, P. M. (1997). Reducing the risk: Connections that make a difference in the lives of youth. Youth Studies Australia, 16(4), 37-50.

Carr, R. A. (1987). The Theory and Practice of Peer Counseling. Victoria, Canada: Peer Resources.

Coggan, C., Patterson, P., \& Fill, J. (1997). Suicide: Qualitative data from focus group interviews with youth. Social Science \& Medicine, 45(10), 15631570.

Comprehensive Health Education Foundation (1997). Natural Helpers: A Peer-Helping Program (3rd ed.). Seattle, WA: Altschul Group Corporation.

Cutrona, C.E. \& Russell, D. (1987). The provisions of social relationships and adaptation to stress. Advances in Personal Relationships, 1, 37-67.

Donald, M., Dower, J., \& Lucke, J. (2000). The Queensland Young People's Mental Health Survey. Brisbane: University of Queensland/Queensland Health.

Frydenberg, E. (1997). Adolescent Coping: Theoretical and Research Perspectives. New York: Routledge.

Glover, S., Burns, J., Butler, H., \& Patton, G. (1998). Social environments and the emotional wellbeing of young people. Family Matters, 49, 11-16.

Kawachi, I. \& Berkman, L.F. (2001). Social ties and mental health. Journal of Urban Health, 78(3), 45867.

Keys Young (1997). Research and Consultation Among Young People on Mental Health Issues: Final Report. Canberra: Department of Health and Family Services.

National Health and Medical Research Council (1997). Depression in Young People: Clinical Practice Guidelines. Canberra: Australian Government Publishing Service.

Prime Minister's Youth Pathways Action Plan Taskforce (2001). Footprints to the Future. Canberra: Department of Education, Training and Youth Affairs.

Rickwood, D., Deane, F.P., Wilson, C.J., \& Ciarrochi, J. (2005). Young people's help-seeking for mental health problems. Australian e-Journal for the Advancement of Mental Health, 4(3), Supplement, www.auseinet.com/journal/vol4iss3suppl/rickwood.pdf

Sawyer, M.G., Arney, F.M., Baghurst, P.A., Clark, J.J., Graetz, B.W., Kosky, R.J., Nurcombe, B., Patton, G.C., Prior, M.R., Raphael, B., Rey, J., Whaites, L.C., \& Zubrick, S.R. (2000). Mental Health of Young People in Australia - Child and Adolescent Component of the National Survey of Mental Health and Well-Being. Canberra: Mental Health and Special Programs Branch, Commonwealth Department of Health and Aged Care.

Weiss, R.S. (1974). The provisions of social relationships. In Z. Rubin (Ed.), Doing Unto Others (pp. 17-26). Englewood Cliffs, NJ: Prentice Hall. 